\title{
KETANGGUHAN RETAK DINAMIK BAHAN KOMPOSIT GFRP UNTUK HELMET INDUSTRI DISEBABKAN BEBAN IMPAK MENGGUNAKAN MSC/NASTRAN FOR WINDOWS
}

\author{
Jusnita \\ Pusat Riset Impak dan Keretakan, Jurusan Teknik Mesin, Fakultas Teknik \\ Universitas Sumatera Utara, Jl. Almamater, Kampus USU Medan 20155
}

\begin{abstract}
ABSTRAK
Penelitian ini menyajikan tentang pengujian yang akan dilakukan dengan menggunakan pendekatan metode elemen hingga dengan spesimen yang berbentuk pelat komposit glass fiber reinforced plastic (GFRP) untuk mengetahui nilai ketangguhan retak dinamik disebabkan beban impak, program simulasi ini dibuat dengan menggunakan soft ware MSC MSC/NASTRAN for Windows dengan sub program FEMAP dengan pembebanan dinamik. Untuk menyederhanakan pada proses simulasi, spesimen digambarkan setengah geometri karena bentuknya yang simetri, demikian pula dalam membuat mesh dapat diatur dengan memperkecil ukuran mesh (fine mesh) pada daerah sekitar ujung retak. Pada pengujian ini beban impak diperoleh dari tegangan yang masuk ke spesimen dengan terlebih dahulu harus mengetahui diameter input bar dan tebal spesimen. Melalui simulasi ini juga akan diketahui propagasi tegangan yang terjadi, proses simulasi dimulai dengan mendefinisikan sifat material, membuat geometri dan pengaturan mesh, menentukan kondisi batas, memberi beban serta melakukan analisa dinamis dengan type analisis adalah transient dynamic/time dan type output displacement and stress. Hasil simulasi elemen hingga menunjukkan distribusi tegangan sama dengan hasil eksperimen dan harga ketangguhan retak dinamik. Adanya perbedaan besar tegangan adalah disebabkan konsentrasi tegangan yang terjadi pada ujung retak (pre crack)
\end{abstract}

Kata kunci: Ketangguhan retak dinamik, GFRP, beban impak, faktor intensitas tegangan kritis.

\section{PENDAhuluan}

Perkembangan bidang konstruksi dalam dunia industri terhadap kebutuhan material teknik semakin meningkat dewasa ini. Hal ini terlihat dengan meningkatnya permintaan terhadap bahan-bahan teknik yang tergolong memiliki kualitas yang lebih tinggi, misalnya; dalam hal kemampuan (sifat-sifat mekaniknya), harganya lebih murah dan banyak dijual di pasaran. Dalam pengembangan teknologi dan proses seperti; bidang konstruksi, produksi atau manufaktur sangat erat hubungannya dengan sifat-sifat mekanik yang dimiliki oleh suatu material, khususnya dalam bidang teknik material yang semakin hari semakin sulit dipenuhi oleh bahanbahan yang ada selama ini.

Guna menjawab tantangan disebabkan dampak dari suatu kemajuan teknologi material yang telah banyak digunakan sebagai bahan dasar dari berbagai sektor industri, maka penulis cenderung untuk melakukan penelitian lanjutan yaitu tentang jenis material komposit polimer yang akan digunakan sebagai bahan dasar untuk pembuatan suatu produk (helmet industri) menggunakan pendekatan elemen hingga.

Penyelidikan dan pengujian terhadap kehandalan dan kekuatan helmet telah dilakukan oleh beberapa peneliti dan balai pengujian yang mengkaji beberapa aspek yang berbeda, Thomson, R.D, [1] melakukan penyelidikan tentang kekuatan dan ketahanan helm industri terhadap beban transversal, yang mana penelitian tersebut menghasilkan beban transversal cenderung lebih mempengaruhi kontur/bentuk helmet industri.

Penelitian helm industri juga telah dilakukan secara simulasi komputer dengan menggunakan pendekatan elemen hingga oleh Nayan [2], dengan menyelidiki perilaku yang terjadi pada helm disebabkan benda jatuh dari ketinggian 40 meter. Penelitian tersebut menyimpulkan bahwa tulangan sangat mempengaruhi kosentrasi tegangan. Penyelidikan dan pengujian tentang cedera pada kepala dan otak yang 
didisebabkankan oleh beban impak kecepatan rendah telah dilaporkan oleh para peneliti pada bidang Biomechanics atau Bioengineering.

Helmet industri yang terbuat dari bahan polimer Ethylene Propelene Copolymer (EPM) yang mengalami prilaku mekanik yang berbeda antara pembebanan impak kecepatan rendah dan impak kecepatan tinggi. Besar kecilnya beban impak yang diterima helmet tergantung pada tinggi rendahnya suatu benda yang jatuh.

Helmet yang banyak digunakan dikalangan industri Indonesia umumnya masih belum memenuhi syarat keselamatan kerja, artinya helmet tersebut tidak menjamin sipemakai akan aman dari benda jatuh bebas dari ketinggian tertentu.

Ditinjau dari segi kekuatannya masih belum mampu atau tahan terhadap benturan benda keras, sehingga mengdisebabkankan terjadinya cedera kepala,[3]. Syam, B, [4] melakukan penelitian tentang ketangguhan retak dinamik dan kerusakan mekanik GFRP untuk faktor intensitas tegangan.

Selain itu juga tingkat kenyamanan suatu helmet industri perlu menjadi perhatian yang spesifik, ini disebabkan pemakaian helmet yang relatif lama oleh para pekerja. Sehingga perlu kenyamanan, dalam hal ini tidak terasa panas, tidak berat yang mengdisebabkankan ketidak betahan si pemakai,[5].

\section{METODOLOGI PENELITIAN}

Bahan yang digunakan untuk uji material dari bahan komposit polimer terdiri dari dua atau lebih bahan campuran seperti:

Material penyusun pelat komposit GFRP adalah:
a. Bahan matriks adalah Unsaturated Polyester Resin BQTN 157-EX
b. Bahan serat serat E-glass sebagai penguat.

c. Bahan pengeras (hardener) atau katalis.

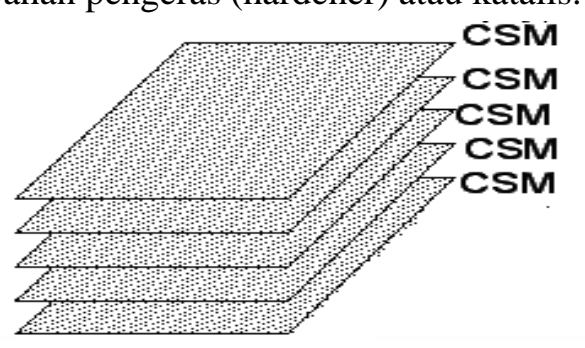

\section{Gambar 1. Gambar susunan serat pada pelat GFRP lima lapis.}

Spesimen dibuat dalam bentuk pelat komposit GFRP diproduksi dengan metode hand lay-up, yang terdiri dari lima lapisan serat Chopped Strand Mat (CSM) seperti pada gambar 1.

\section{Prosedur Pelaksaan Penelitian}

\section{A. Penelitian secara ekperimental}

Alat uji yang digunakan dalam penelitian ini adalah KOMPAK seperti yang diperlihatkan pada gambar 3. Susunan batang pengujian terdiri atas striker, input bar dan pelat. Sifat mekanik dan geometri batang impak dan batang penerus ditunjukan pada tabel 1. Beban impak yang menghantam striker dihasilkan oleh udara yang bertekanan, hingga akhirnya gelombang tegangan tekan masuk kespesimen pelat. Gelombang yang merambat pada batang dideteksi dengan menggunakan semiconductor strain gage yang dipasang pada dua lokasi pada jarak $200 \mathrm{~mm}$ dan $400 \mathrm{~mm}$ dari ujung batang penerus. Selanjutnya dengan bantuan bridge box, perubahan tahanan gage $\Delta \mathrm{R} / \mathrm{R}$ diubah menjadi voltase output $\mathrm{Vo}$ pada transient conveter, melalui signal conditioner.

Data gital direkam transient converter selanjutnya dikirim ke komputer melalui interface dua channel. Hasilnya dapat dimunculkan berupa grafik tegangan fungsi waktu (strees history). Perhitungan tegangan insiden pada lokasi impak (permukaan spesimen pelat dan input bar) didasarkan pada sebuah teori rambatan gelombang elastis satu dimensi. 


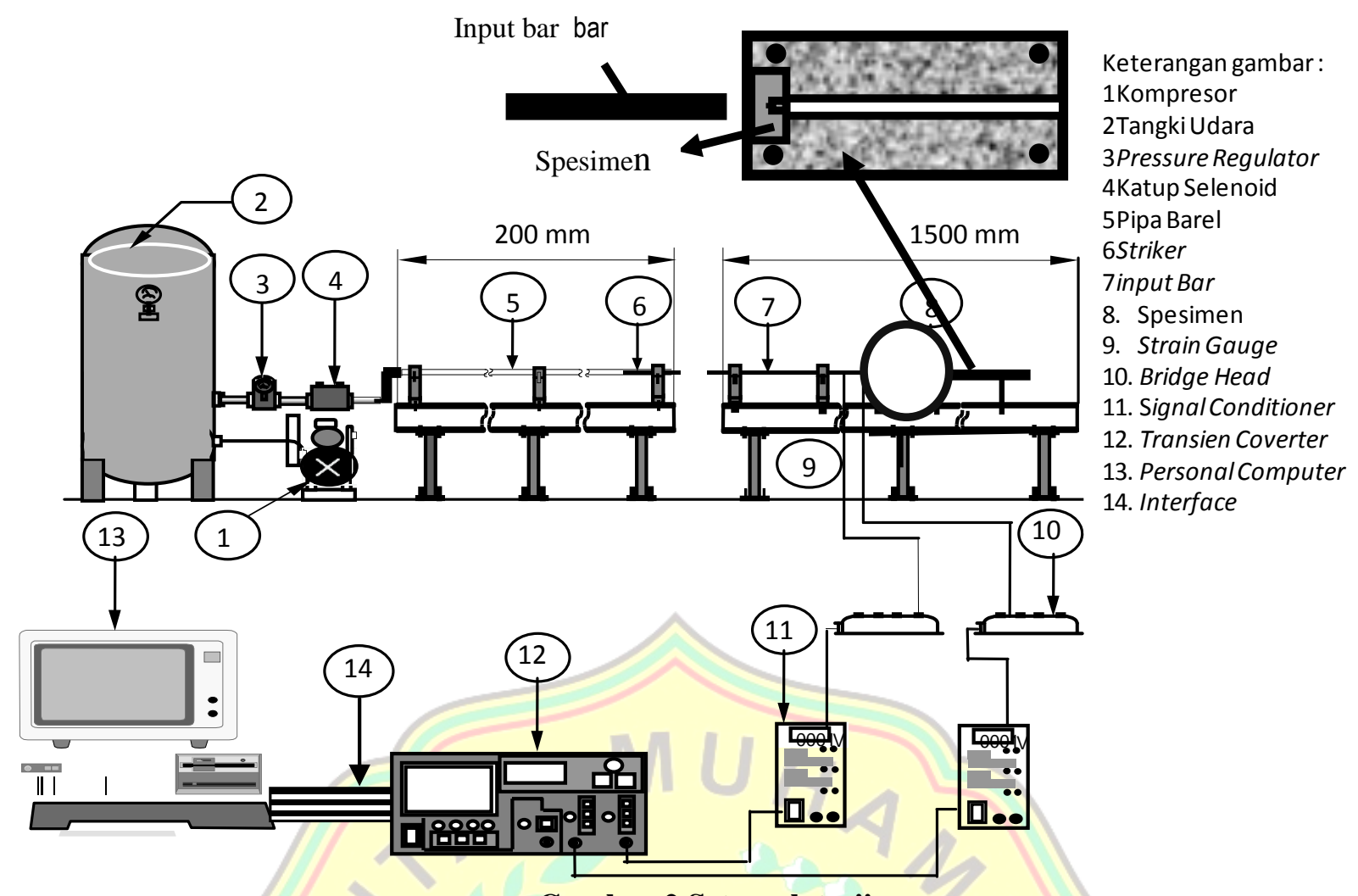

Gambar 2.Setup alat uji

\section{B. Penelitian Secara Simulasi Komputer}

Simulasi dengan menggunakan komputer dilaksanakan di IC-ATAR USU. Software yang digunakan adalah MSC/NASTRAN for Windows yang berbasis metode Elemen Hingga (MEH). MSC/NASTRAN mampu menyelesaikan persoalan-persoalan struktur dan material untuk menganalisa tegangan (stress), perpindahan panas (head transfer) dan (vibration) dengan mengimpor geometri CAD (Computer Aided Design). Kajian numerik yang umum digunakan dilakukan dengan dua cara yaitu dengan beda hingga dan elemen hingga. Beda hingga (finite difference) dilakukan dengan mendiskretisasikan persamaan diferensial. Metode ini memiliki kelemahan utama yaitu syarat-syarat batasnya sangat sulit dipenuhi. Dan kelemahan yang lain adalah akurasi hasil perhitungannya yang relatif rendah. Kajian elemen hingga adalah analisi pendekatan yang berasumsi peralihan atau asumsi tegangan atau berdasarkan kombinasi keduanya pada setiap elemennya. Simulasi komputer untuk mengklarifikasi perilaku mekanik yang terjadi disebabkan pengujian secara experimental.

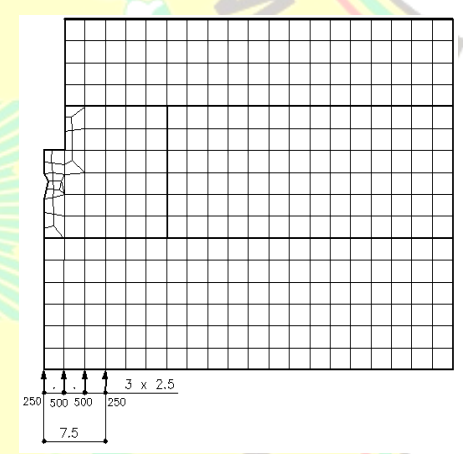

\section{Gambar 3. Model simulasi dengan MSC/NASTRAN}

\section{HASIL DAN PEMBAHASAN}

Hasil simulasi yang telah dianalisa dengan type analisis adalah transient dynamic/time dan type output displacement and stress dapat ditunjukkan pada gambar 4 pada kontur tegangan utama (VonMises) gaya sebesar $1500 \mathrm{KN}$, tegangan yang terbesar terjadi didaerah yang kritis yaitu diujung retak (pre crack) yang berwarna merah ditunjukan dengan tanda panah tegangan utama yang terjadi sebesar $50 \mathrm{MPa}$ dan terdapat pada elemen 318 (case 27, $\mathrm{t}=21,58 \mu \mathrm{s}$ ).

Didaerah ini spesimen mengalami kegagalan, karena tegangan yang terjadi tidak boleh 
melebihi dari batas maksimum tegangan yang diizinkan diujung retak (pre crack), seperti yang diungkapkan oleh Joseph e. Shigley Larry D. Mitchell, tentang teori kegagalan (Failure Theories).

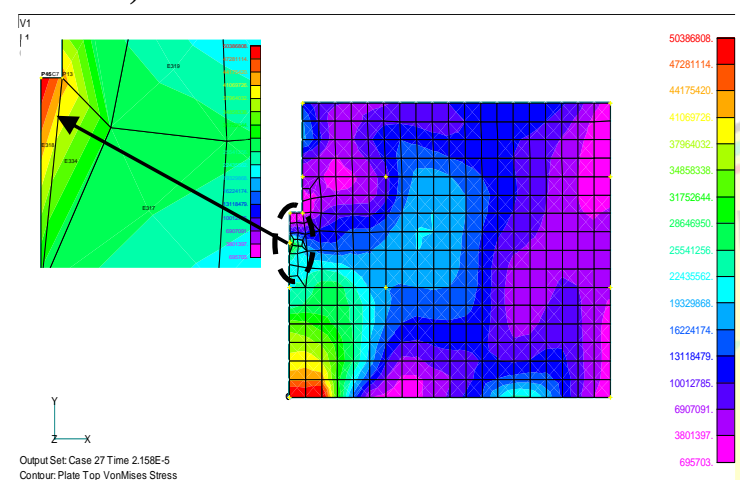

Gambar 4 Distribusi tegangan utama (MPa)

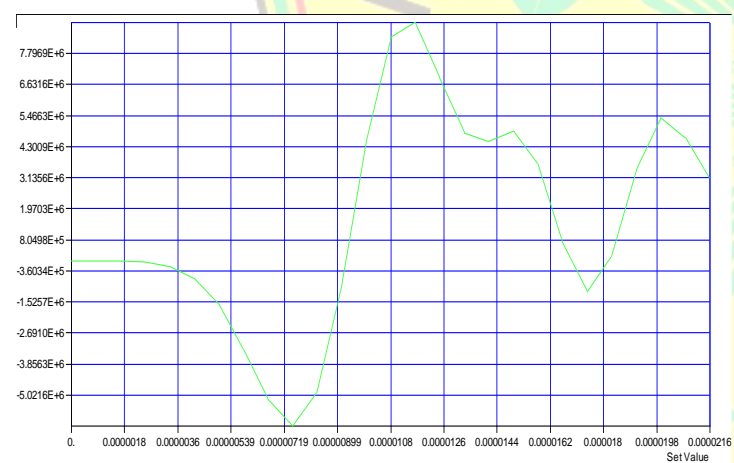

Gambar 5. Grafik tegangan utama (MPa) vs waktu $(\mu s)$

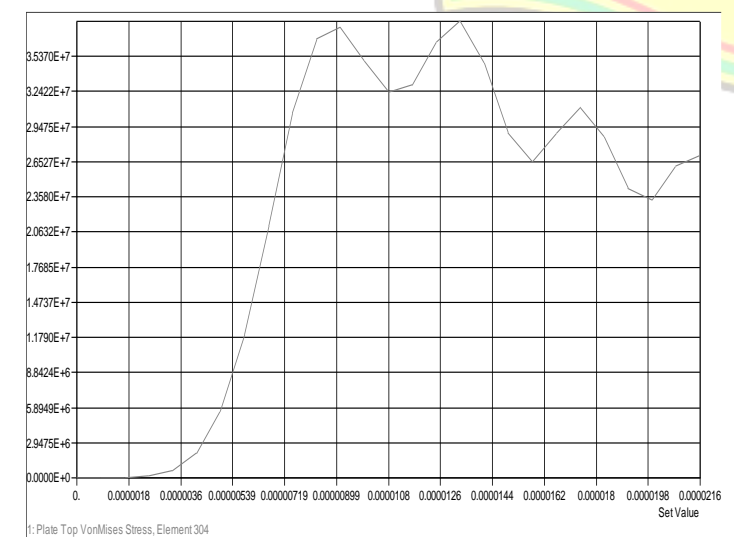

Gambar 6. Grafik tegangan vs waktu

Gambar 6. menunjukan grafik tegangan utama vs waktu yang terjadi diujung retak (pre crack). Pada gambar 7 dijelaskan distribusi tegangan normal arah $\sigma x$ yang terjadi sebesar 56 MPa dan grafik tegangan utama vs waktu arah $\sigma \mathrm{x}$ yang ditunjukan pada gambar 8

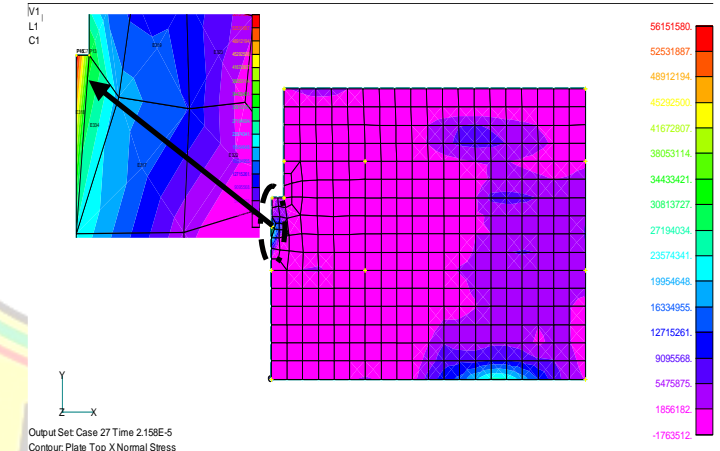

Gambar 7 Distribusi tegangan utama (MPa) $\operatorname{arah} \mathrm{x}$

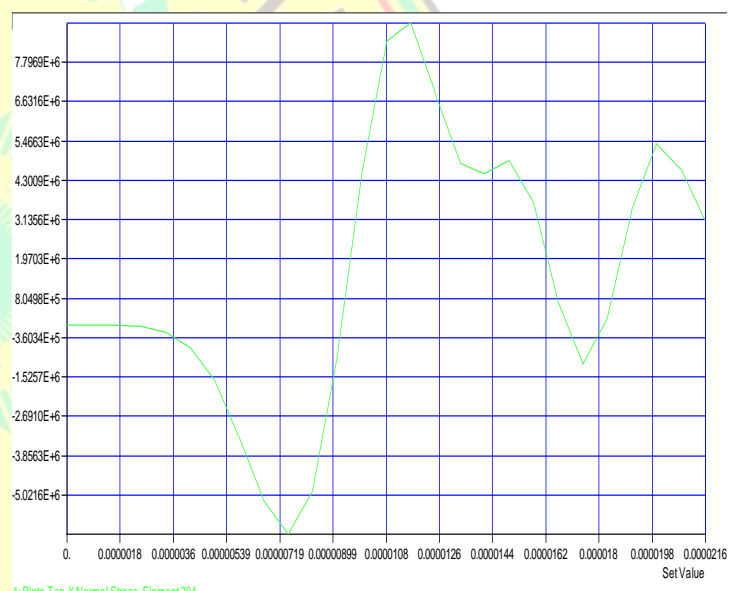

Gambar 8. Grafik distribusi tegangan utama (MPa) vs waktu ( $\mu s)$ arah $x$

Gambar 9 menunjukan tegangan normal arah $\sigma y$, tegangan normal terjadi sebesar $19 \mathrm{MPa}$ dan gambar 10 menunjukan grafik tegangan utama vs waktu arah oy dengan waktu, tegangan dan elemen yang sama dengan gambar 5

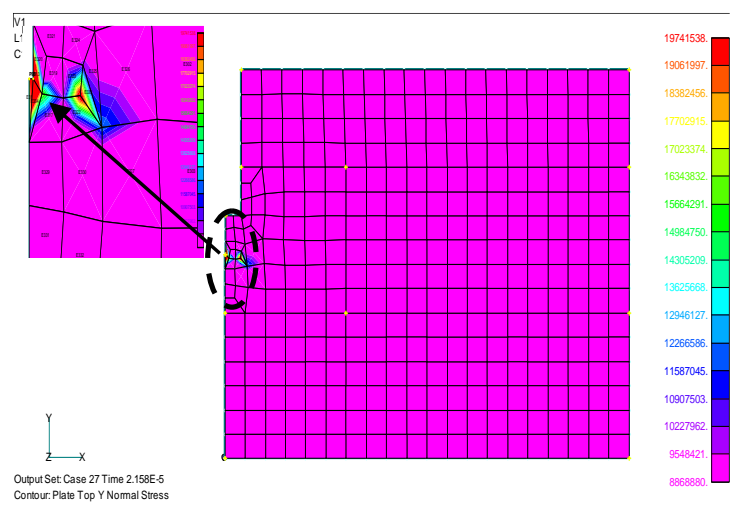

Gambar 9. Distribusi tegangan utama (MPa) $\operatorname{arah} \mathbf{y}$ 


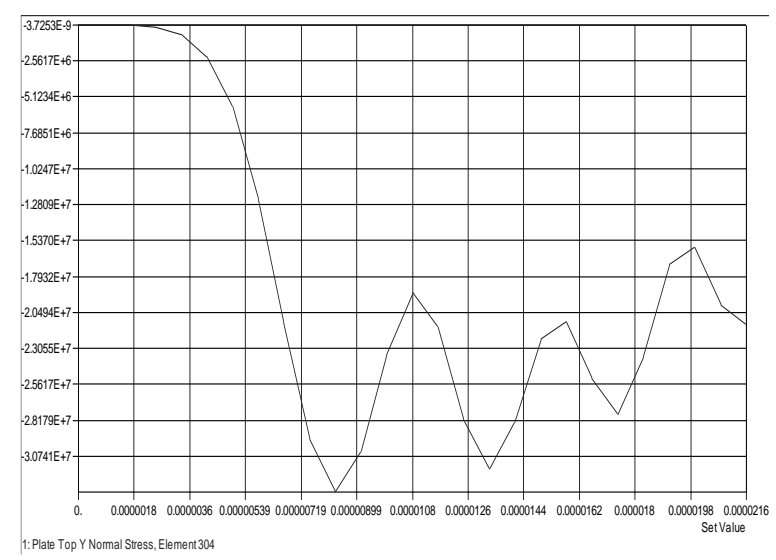

Gambar 10. Distribusi tegangan utama (MPa) vs waktu $(\mu s)$ arah y

Bila diamati dari ketiga grafik tersebut, tegangan terbesar terjadi pada arah sumbu $\sigma x$ karena gaya terpusat pada arah $\mathrm{x}$. Dilihat pada waktu dan elemen yang sama maka dapat diambil kesimpulan, bahwa spesimen mengalami kegagalan apabila melebihi batas maksimum tegangan yang diizinkan diujung retak (pre crack) yang dikenai beban impak.

\section{Ketangguhan Retak Dinamik}

Ketangguhan retak dinamik sebagaimana dijelaskan pada artikel terdahulu [2], merupakan prilaku mekanik yang harus diketahui untuk diaplikasi pada konstruksi yang mengalami pembebanan secara tiba-tiba. Informasi harga ketangguhan retak dinamik dapat diperoleh dengan mengetahui terlebih dahulu tegangan yang terjadi di sekitar ujung retak (crack tipe).

Dengan mengasumsi perletakkan strain gauge terletak pada elemen 304 akan menghasilkan kontur tegangan utama (VonMises) yang terjadi. Dengan menggunakan persamaan 2.2 maka harga ketangguhan retak dinamik dapat ditentukan sebagai berikut;

$$
\begin{gathered}
K_{I D}=\sigma \sqrt{\frac{8}{3} \mu r} \\
=49,25 \sqrt{\frac{8}{3} \pi \cdot 0.007} \\
=11,93 \mathrm{MPa} \sqrt{m}
\end{gathered}
$$

Pada tabel 2. dapat dilihat, dengan menvariasikan beban yang diberikan maka akan menghasilkan tegangan, regangan dan stress intensity critical factor yang bervariasi. Tegangan yang terjadi pada elemen 304 diambil dari nilai rata-rata tertinggi dari tegangan utama (VonMises). Dapat diambil kesimpulan makin besar beban yang diberikan makin besar pula tegangan, regangan dan stress intensity critical factornya.

Tabel. 2. Harga stress intensity critical factor pada daerah strain gauge

\begin{tabular}{ccccc}
\hline No. & $\begin{array}{c}\text { Beban } \\
(\mathbf{F})\end{array}$ & $\begin{array}{c}\text { Tegangan } \\
(\boldsymbol{\sigma})\end{array}$ & $\begin{array}{c}\text { Regangan } \\
\mathbf{( \varepsilon )}\end{array}$ & $\begin{array}{c}\text { Stress intensity } \\
\text { critical factor } \\
\left(\mathbf{K}_{\mathbf{I}}\right) \mathbf{M P a} \sqrt{m}\end{array}$ \\
\hline 1. & 1500 & 38 & $2,88 \times 10^{-}$ & \\
& & & 3 & 9,2 \\
2. & 1800 & 45 & $3,4 \times 10^{-3}$ & 10,9 \\
3. & 2100 & 53 & $4 \times 10^{-3}$ & 12,8 \\
4. & 2400 & 61 & $4,6 \times 10^{-3}$ & 14,8 \\
\hline & rata- & 49,25 & $3.72 \times 10^{-}$ \\
& rata & & 3 & 11,93 \\
\hline
\end{tabular}

Harga ketangguhan retak dari data hasil simulasi di atas dapat diklarifikasi kembali dengan hasil yang diperoleh secara eksperimen yang telah dilakukan peneliti sebelumnya [6] yaitu sebesar $12 \mathrm{MPa} \sqrt{m}$, dilihat dari hasil simulasi (tabel 4.1) dengan mengambil nilai ratarata stress intensity critical factor dan tegangan yang terjadi, diperoleh sebesar 11,93 MPa $\sqrt{m}$. Karena untuk memperoleh nilai stress intensity critical factor pada simulasi belum bisa dianlisa secara tepat karena adanya perbedaan asumsi yang diambil dengan Kondisi yang sebenarnya. Dan hasil ketangguhan retak dinamik dari uji simulasi ini, juga dapat dibandingkan dengan hasil uji statik, yaitu sebesar $10 \mathrm{MPa} \sqrt{m}$. Pada grafik regangan vs stress intensity critical factor $\left(\mathrm{K}_{\mathrm{I}}\right)$ (gambar 4.12) dijelaskan bahwa besarnya regangan menyebabkan stress intensity critical factornya menjadi besar, sehingga regangan mempengaruhi stress intensity critical factor. 


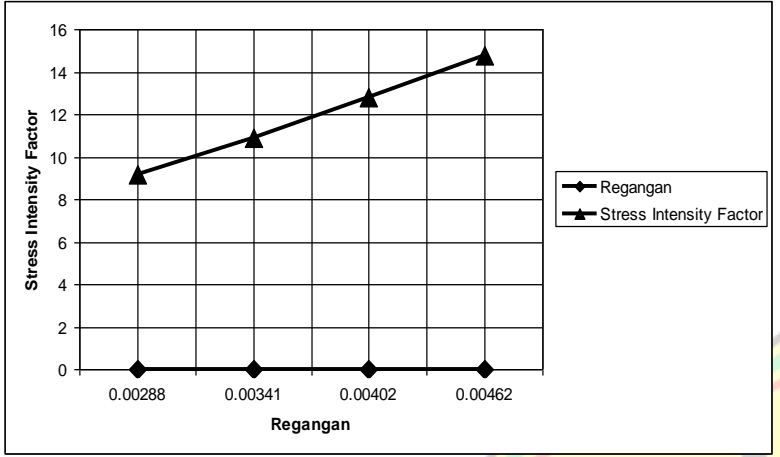

Gambar 11. Grafik regangan vs stress intensity critical factor

Hasil simulasi elemen hingga menunjukkan distribusi tegangan sama dengan hasil eksperimen dimana distribusi tegangan yang terjadi pada eksperimen $50 \mathrm{MPa}$ dengan ketangguhan retak dinamik $12 \mathrm{MPa} \sqrt{m}$, pada simulasi 49,25 MPa dengan harga ketangguhan retak dinamik 11,93 $\mathrm{MPa} \sqrt{m}$. Adanya perbedaan besar tegangan adalah disebabkan konsentrasi tegangan yang terjadi pada ujung retak (pre crack), dengan demikian cara simulasi juga memberikan tingkat akurasi yang tinggi. Dari perbandingan di atas juga dapat dijelaskan bahwa ketangguhan retak dinamik akan memberikan respon yang berbeda dengan ketangguhan retak melalui uji statik, di mana harga ketangguhan retak statik lebih rendah dari ketangguhan retak dinamik.

\section{KESIMPULAN}

Dari hasil simulasi pelat GFRP dengan menggunakan perangkat lunak MSC/NASTRAN for windows dapat disimpulkan bahwa:

1. Dengan menggunakan simulasi elemen hingga dapat diketahui distribusi tegangan pada sebuah pelat dari bahan GFRP yang diberi beban impak sebesar 49,25 $\mathrm{MPa}$ sedangkan pada eksperimental $50 \mathrm{MPa}$.

2. Inisiasi keretakan terjadi disebabkan terkonsenterasinya tegangan tarik pada lokasi tertentu didalam pelat, dan bentuk retak ditentukan oleh geometri, arah, dan besarnya pembebanan.

3. Faktor intensitas tegangan kritis untuk Material komposit GFRP dengan menggunakan simulasi elemen hingga
MSC/NASTRAN for Windows diperoleh sebesar11,93MPa $\sqrt{m}$, pada eksperimen-tal $12 \mathrm{MPa} \sqrt{m}$.

4. Ketangguhan retak (fracture toughness) diperoleh bila harga intensitas tegangan mencapai harga kritis.

5. Simulasi mampu memperkirakan perkembangan retak.

\section{DAFTAR PUSTAKA}

UU. K3, no.1 Tahun 1970

Industrial Safety Equipment Association, 1901 North Moore Street, Suite 808 Arlington, Virginia 22209.

Thomson, R.D., S.P. Duckworth, A.Birkbeck, and M.T.Cassidy, The Performance of Industrial Safety Helmets Under Transverse Loading, Technology, Law and Insurance, 1997 2, 1-6.

Nayan, A,. Bustami Syam, Penyelidikan Perilaku Mekanik Helmet Industri Disebabkan Beban Kecepatan Tinggi, Prosiding Seminar Material dan Struktur (MASTRUCT), Medan, Januari, 2004

Yu T., J. Wu, and X. Chen, A Survey on the Usage of Hard Hats in Hong Kong Construction Sites, and a Study on the Protections of Safety Helmets, March 1999, http://www.osche.org.hk

Syam B, Dynamic Fracture Toughness and Damage Mechanisms Of GFRP Subjected to Short Pulse Stress Intensity.

Hasrin, Bustami Syam, Pabrikasi dan Ergonomik Helmet Indutri, tesis 2007

Gibson, R.F, Principles of Composite Material Mechanics, Mc Graw Hill, New York, 1994.

Fried, R, Joel, Polymer science and Technology, University of Cincinnati, Prentice Hall, New Jersey, USA, 1995

Syam B, Kouji Nakazato, and Hiroomi Homma, Dynamic Fracture Touughness and Damage Mechanicanisms of GFRP Subjected to Short Pulse Stress Intensity, Proc. $3^{\text {rd }}$ Internasional Symposium on Impact Engineering, Sinagpore, pp 172177, 1999. 
Syam B, Simulasi elemen hingga pada pelat yang mengalami beban impak

Syam B, Nayan, A,. Klarifikasi Retak Pelat Plaster Disebabkan Beban Impak Menggunakan MSC/Nastran, Proceeding, Regional Seminar on Numerical Analysis in Engeneering (NAE), 99

Shirley SL, Hiroomi HOMMA, Approach to Dynamic Fracture Toughness of GFRP from Aspect of Viscoelastic and Debonding Behaviors, Vol. 1,No. 3,2007.

Chawla, Krishan, Composite Material, Firs Edition, Berlin Spring-Verlag, New York Inc, 1987

Warner, B, Steve, Fiber Science, University of Massachusetts, Prentice Hall, New Jersey, USA, 1995.

Fried, R, Joel, Polymer science and Technology, University of Cincinnati, Prentice Hall, New Jersey, USA, 1995

T.L. Anderson, Fracure Mechanics Fundamentals and Applications

Dailly, James W, Instrumentation for Engineering | Measurement, Second Edition, New York, Jhon Willey \& Son, Inc, 1993

Richard W. Hertzbergl, Deformation and Fracture Mechanics of Engineering Material

Kolsky, H, An Investigation of the Mechanical Properties of Materials at Very High-
Rate of Loading, Proc. Phys. Soc, London, B62, 676-700, 1949.

Joseph E. Shigley and Mitchell, Larry.D, (1999), "Mechanical Engineering Design", Edisi ke empat, Jilid 1, Terjemahan Ir.Gandhi Harahap M.Eng. Erlangga, Jakarta.

Syam B, Aplikasi Teknik Dua Gage Dalam Pengukuran Tegangan Indisinden Pada Helmet Industri yang Dikenai Beban Impak Kecepatan Tinggi, Journal Ilmiah SINTEK, Vol 19, no.2, 2003.

SME Standard Method of Test for Elastic-Plastic Fracture Taughness $\quad \mathrm{J}_{\mathrm{IC}}-\mathrm{S} 001$ 1981,JSME, 1981.

Timing, R.L, Engineering Material, Vol $1,2^{\text {nd }}$ edition, UK, 1998

Takayuki KUSAKA, Experimental Characterization of Interlaminar Fracture Behavior in Polymer Matrix Composites under Low-Velocity, JSME International Jounal Vol. 46, No. 3, 2003.

Luisa Moreno, Impact Fracture Toughness of Polyethylene/Polypropylene Multilayers, Polymer Engineering And Science, September 2004, Vol.44, No.9.

Masaki HOJO, Taketoshi YAMAO, Effect of Interface Control on Mode I Interlaminar Fracture Toughness of Woven $\mathrm{C} / \mathrm{C}$ Composite Laminates. JSME, International Journal, Vol. 44, 2001. 